\title{
Research on Current Situation and Perfection Strategies of Enterprise Intellectual Property Management
}

\author{
Lanying Gao, Qiong Jiang, Chuanlin Huang, Baojie Li \\ Law School, Guilin University of Electronic Technology, Guilin, 541004, China
}

Keywords: Enterprise intellectual property; Management status; Perfection strategies

\begin{abstract}
The intellectual property is an immaterial asset with long history, and such asset has gradually become the key for stable development of society and enterprises. As for enterprises, how to manage and utilize continuously increased intellectual property in an orderly way has become a new challenge in their development. Based on this situation, this paper mainly carries out a discussion on the current situation and perfection strategies of enterprise intellectual property management.
\end{abstract}

\section{Introduction}

The essence of enterprise intellectual property strategies is the overall planning and a series of strategies and means adopted by enterprises to seek for advantageous position in market competition by use of the features of intellectual property and its system. Under the big background that China has issued national intellectual property strategies, the implementation of enterprise intellectual property strategies is greatly necessary and urgent, and it needs to take national intellectual property strategies as guidance to promote enterprise intellectual property work from perspective of creation, management, protection, and application of intellectual property. How to protect the enterprise intellectual property and realize maximized utilization of intellectual property is the core content of enterprise intellectual property operation and management. While China's intellectual property system is increasingly perfect, many enterprises also have known the function of intellectual property in enterprise operation and management; however, due to lack of experience in intellectual property management practice, it is unable to timely find out effective management entry points and management strategies. How to avoid the potential problems in the intellectual property operation and management practice, improve intellectual property management, and promote enterprise competition is a difficulty faced by many enterprises in their intellectual property management work.

\section{Brief description of enterprise intellectual property management}

The operation and management of enterprise intellectual property is the special function of enterprises for the purpose of effectively protecting and standardizing enterprise intellectual property, showing the important strategic position and function of enterprise intellectual property system in enterprise development, and reasonably using the intellectual property system; from legal, practical, and scientific perspective, it is the systematic organization, arrangement, and planning activity made for the creation, protection, production, and operation of enterprise intellectual property. The optimization of enterprise intellectual property system can be divided into three stages: (1) to establish perfect intellectual property system, and make the system effectively operate and exert its function; (2) to improve the overall structure and use function of intellectual property system and further exert the overall function; (3) to enhance the scientificity and updating ability of enterprise intellectual property system.

The reform in operation and management of China's enterprise intellectual property can be divided into following four points: (1) change from material cultural asset management to intangible cultural asset management; (2) development from material asset management to scientific knowledge management; (3) change from traditional thinking management to new thinking management; (4) transition from rigid management to flexible management. According to above data, it can be seen that to create the enterprise intellectual property management system suitable for enterprise system in 
new era and comprehensively improve the production, operation, and management level of China's enterprise intellectual property is an inevitable result under international and domestic trend. As the subject in socialist market economy, the enterprises shall greatly improve their own value and core competitiveness, which is the only way for them to obtain the best economic benefits.

\section{Problems existing in enterprise intellectual property management}

\section{Degree of enterprises' understanding of intellectual property management}

Due to enterprises' own property and cultural concept, the staffs often pay great attention to tangible material asset but ignore the intangible immaterial asset -- intellectual property and regard it as accessory, and they are satisfied with a smattering of knowledge of the field of intellectual property; meanwhile, many management personnel pay insufficient attention to the problems caused by intellectual property, which causes the situation that the below follows the behavior of the above; there is neither timely application for patent nor strict confidentiality for technology, and the lack of awareness of property also drives the lack of whole enterprise departments on relevant knowledge and training. In this way, except that the technical personnel are unconcern about scientific research and development, the enterprise management personnel have unclear understanding of special position and function played by intellectual property in enterprise production, operation, and development, which further increases the investment in fund, equipments and products and weakens the protection on intellectual property.

\section{Enterprise construction of intellectual property management system}

The enterprise intellectual property management includes overall strategic deployment, design of rules and systems, basic-level personnel training, supervision of operation and management link, actual implementation and utilization, innovation and classification, etc. It is contained in the links of creation, protection, and utilization of intellectual property, and the creation, protection, and utilization of intellectual property can’t be separated from effective management of intellectual property. However, there exist many practical problems in most of China's enterprises, such as imperfect intellectual property management system, imperfect innovation incentive mechanism, lack of coordinative and uniform mechanism, and low level of strategic deployment and planning.

\section{Lack of coordinative mechanism between enterprise intellectual property and department}

Currently, the coordinative mechanism among management departments related to intellectual property is imperfect, and the operation policy is not linked with management concepts, which causes the situation that the enterprise management can't be banded together like strands of a rope. The consequence is that there are instructions from many superior departments as for some affairs, but no instruction from any management personnel as for some affairs; finally, it is unable to form a whole with harmonious and uniform management. For example, in the negotiation of international business, each relevant department has the participation of different degree, but they express respective views without uniform thoughts, thus it is unable to unite together; while some academic problems and international intellectual property problems met by the enterprises in the negotiation process can't be timely solved, the time loss is caused; while the foreign merchants or foreign governments want to get a more detailed knowledge of specific content of intellectual property, they shall communicate with many departments which show different opinions; many foreign merchants make use of imperfect coordinative mechanism to exploit an advantage. In the beginning of 1990s, China once tried to establish and perfect the intellectual property system; however, under the tide of institutional reform, such action was not practically implemented, which caused many inconveniences to the foreign development of domestic enterprises.

\section{Enterprise intellectual property, production and operation}

There is whole-course connection between enterprise intellectual property management and enterprise production and operation policies; through combination of intellectual property deployment and enterprise operation and management concept, it is able to effectively improve enterprise innovation ability and avoid potential risk. Currently, most of enterprises only pay attention to the acquisition of intellectual property, but ignore the management on intellectual 
property ownership problems in the links of product research and development, packaging and production, sales channel, and personnel management in the operation and management activities. Furthermore, the enterprises don't establish perfect award and incentive mechanism, industrialization mechanism, dispute management mechanism (solution for dispute of enterprise intellectual property, and measures adopted after the right is infringed), information management mechanism, contract management mechanism related to intellectual property, and other contents.

\section{Enterprise intellectual property and enterprise management personnel}

The technological management work of intellectual property integrates technical management, economic management, and legal management together, thus it has high requirements for personal ability. However, most of enterprises have insufficient knowledge of intellectual property rights, and pay little attention to management work, which causes the situation that the management post is held by personnel of other work posts, and the staffs don't take this as work center and performance assessment center; therefore, the staffs have insufficient original power to learn and explore the business knowledge; besides, some management staffs are not professional. The professional degree of staffs' management ability remains to be enhanced.

\section{Perfection strategies of enterprise intellectual property management}

\section{To establish a perfect enterprise intellectual property management}

In terms of the problem that the enterprises have weak awareness of protecting the intellectual property, all staffs of the enterprises shall change their ideology, transfer their focus from material asset to immaterial asset - intellectual property, and pay high attention to intellectual property; in particular, the high-level management personnel inside enterprises shall enhance management and application of enterprise intellectual property. Meanwhile, the function played by basic-level staffs in the intellectual property management also can't be ignored; from perspective of shaping operation and management concepts, the enterprises shall actively cultivate and improve staffs' knowledge of intellectual property so that it is convenient for the enterprise intellectual property management to be implemented. Each staff shall not only get basic knowledge of intellectual property, but also be concerned about the enterprises, pay attention to the trend of national intellectual property, and timely know the methods of protecting enterprise intellectual property. The enterprise shall blend the knowledge of intellectual property into enterprise staffs' daily training, and the human resources department of enterprises cooperate with propaganda department to blend the content of intellectual property into enterprise culture; this method can help to improve staffs' actual level of intellectual property knowledge.

\section{To perfect intellectual property management system}

The systematic theoretical mechanism behind this management work promotes the formation of system, repairs the system work, and provides systematic support for management measures. The management system of enterprise intellectual property is an organic, coordinated, and uniform system jointly constructed by many kinds of operation and management integration modules with different functions and emphases, and it mainly includes the formulation and perfection of intellectual property management, organization and leadership structure, intellectual property protection system, human resources management, information file management and other contents. The foundation of intellectual property management is to further expand the intellectual property strategies, and lay a foundation for developing complicated business and improving management level, which has obvious effect on enhancing the basic operation and management work of intellectual property management work, promoting the right development and utilization of intellectual property, and promoting intellectual property operation and management concepts. A perfect intellectual property operation and management system shall have clear management objectives, specially-assigned persons to be responsible for special department, clear responsibilities, standard and correct work process, and closely linked work procedure, as well as reflect high unification of intellectual property system, and organic combination of clear responsibilities, uniform management, and decentralized management. A good intellectual property work system can help to 
include the intellectual property management work into the scope of enterprise operation and management. After the construction of basic system of enterprise intellectual property operation and management is completed, the enterprises shall utilize the basic rules in production of intellectual property, right protection, and right utilization to continuously adjust the emphases of management system and perfect the foundation of management system.

To establish perfect, authoritative, and effective coordinative institution of intellectual property management

The operation and management of intellectual property penetrate through creation, protection, and application process of intellectual property; the details of intellectual property involves many aspects of policies, thus it is impossible to let one management department carry out uniform management, and such management shall be made under active cooperation and coordination of many departments. In order to coordinate the problems existing in intellectual property management departments, an authoritative and effective intellectual property management institution shall be set up. We can borrow ideas from the experience of American creating intellectual property system, and establish a national intellectual property management committee directly led under the national organ of supreme power - the State Council. This committee shall take the ministries and commissions related to intellectual property management and protection work as member units, and establish various kinds of counselor and expert groups which consists of relevant experts, and representatives of enterprise circle and intellectual property intermediaries. The main responsibilities of the committee shall include: researching and protecting national intellectual property strategies and policies; coordinating intellectual property management departments, and unifying the opinions of departments; organizing to learn and research cross-department strategic problems and policies; supervising and checking strategic deployment of departments and implementation condition of national policy. In order to alleviate the workload of committee, it is able to add a simple office to carry out daily organization, coordination, and reception work, and fully exert the function of each counselor group.

\section{Production period for full integration of enterprise intellectual property management system into products}

It is required to fully include the research and development work of intellectual property into various stages such as project approval, production and operation, purchase and management, sales link, and after-sale service so that the production steps of enterprise products and intellectual property management activities can be carried out in an orderly way, each corresponding production and management can be fully controlled, and the enterprise intellectual property management is integrated with enterprise management of operation process; in this way, it is able to fully improve the overall competitiveness of enterprises.

\section{Enterprise intellectual property incentive mechanism and internal talent cultivation mechanism}

The research and development of intellectual property need the hard efforts of work staffs of different departments, and a perfect award incentive mechanism is the important content of the output of enterprise intellectual property. Apple Inc provides 50,000-80,000 yuan of award for its staffs at patent application stage and authorized use stage; if the authorized patent is applied in Apple Inc or other enterprises, it will provide the inventors with hundreds of thousands of yuan every year; while the patent is within the scope of allowable service life, the award is issued every year regardless of whether the inventors are on the job or not on the job. Besides, it is required to enhance cultivating special intellectual property talents. The operation and management work of enterprise intellectual property integrate two factors, that is, technology and laws, thus it has dual feature. We shall enhance the learning and training of special intellectual property personnel and other staffs, actively organize the training of intellectual property knowledge for the highest managers and decision-makers and all staffs, and the discussion on major intellectual property disclosure cases, etc. 


\section{Conclusion}

The key for transformation development from national capital economy to enterprise knowledge-based economy is intellectual property, which is also the foundation for enterprise production and operation as well as national development. We shall not only strictly manage intellectual property, but also regard intellectual property as the future development direction of enterprises and the state, try our best to learn and research intellectual property, respect intellectual property, improve the awareness of intellectual property, and make the intellectual property truly become the symbol of enterprise and national wealth.

\section{Acknowledgments}

This paper is the research result of Guangxi Scientific Research and Technological Development Project "Research on Intellectual Property Trusteeship Service of Middle and Small-sized Enterprises in Guangxi, and the project number is LS14053X.

\section{References}

[1] Xu Junfeng: Discussion on Current Situation and Countermeasures of China's Enterprise Intellectual Property Management, China Invention \& Patent, 2013, (02).

[2] Fan Decheng, Jia Aimei: Analysis on Problems Existing in China's Intellectual Property Management and Countermeasures, Commercial Research, 2014, (05).

[3] Zhou Yan: Intellectual Property Management and Improvement of Enterprise Core Competitiveness, CO-Operative Economy \& Science, 2011, (06).

[4] Shen Shijuan, Liu Haifeng: Government Behavior Mode of Improving the Level of Enterprise Intellectual Property Management, Science \& Technology Progress and Policy, 2011, (24).

[5] Guo Qiumei, Li Yingbo: Construction and Empirical Analysis of College Intellectual Property Work Assessment Indicator System, R\&D Management, 2007, (05).

[6] Jin Yonghong: Japan's Strategic Management of Enterprise Intellectual Property and Its Enlightenments on China’s Enterprises, Science \& Technology and Economy, 2008, (01). 